Imaging System for the Automated Determination

of Microscopical Properties

in Hardened Portland Concrete

Federal Manufacturing \& Technologies

C. W. Baumgart, S.P. Cave, K.E. Linder

KCP-613-6306

Published March 2000

Final Report/CRADA Project Accomplishments Summary

CRADA Number 98KCP1069

Approved for public release; distribution is unlimited.

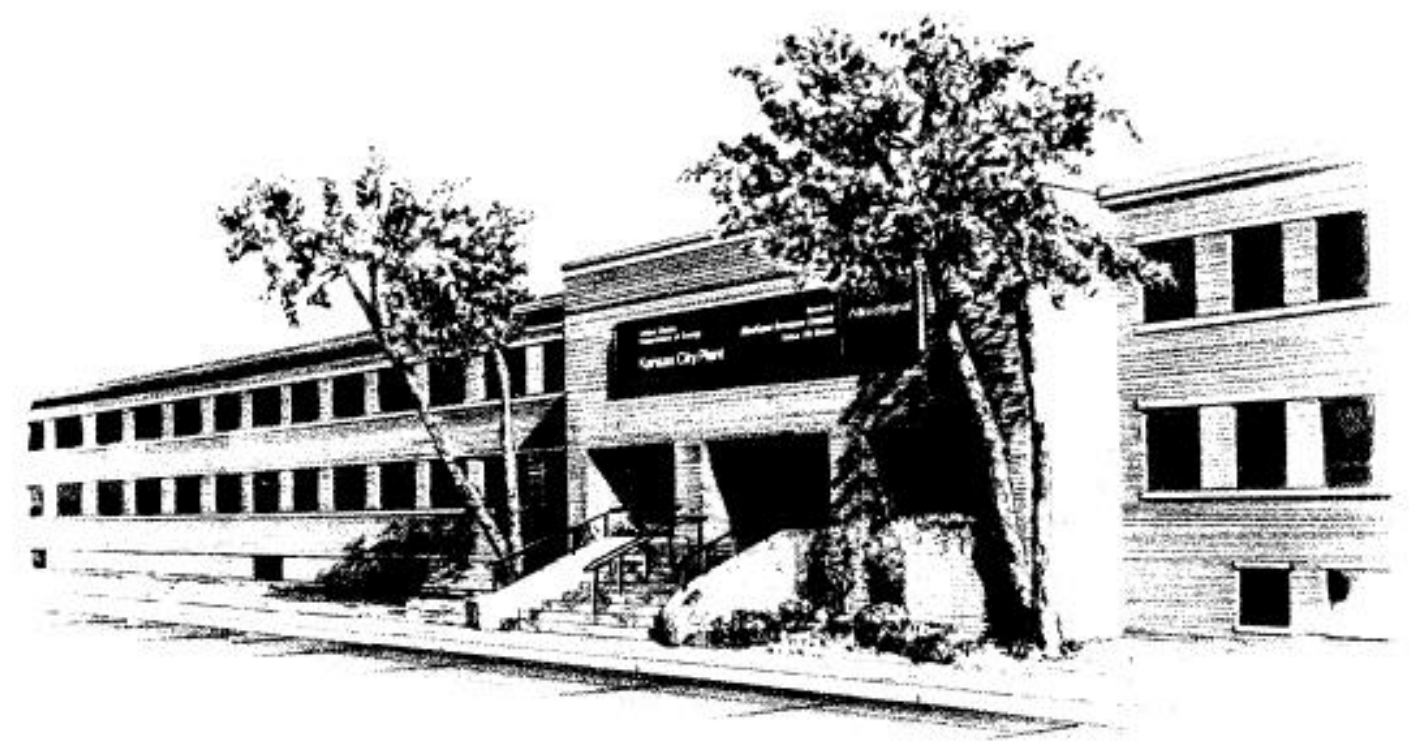

Prepared Under Contract Number DE-ACO4-76-DP00613 for the

United States Department of Energy

\title{
DISCLAIMER
}

This report was prepared as an account of work sponsored by an agency of the United States

Government. Neither the United States Government nor any agency thereof, nor any of their employees, 
makes any warranty, express or implied, or assumes any legal liability or responsibility for the accuracy, completeness, or usefulness of any information, apparatus, product, or process disclosed, or represents that its use would not infringe privately owned rights. Reference herein to any specific commercial product, process, or service by trade names, trademark, manufacturer, or otherwise, does not necessarily constitute or imply its endorsement, recommendation, or favoring by the United States Government or any agency thereof. The views and opinions of authors expressed herein do not necessarily state or reflect those of the United States Government or any agency thereof.

Printed in the United States of America.

This report has been reproduced from the best available copy.

Available to DOE and DOE contractors from the Office of Scientific and Technical Information, P. O. Box 62, Oak Ridge, Tennessee 37831; prices available from (865) 576-8401, FTS 626-8401.

Available to the public from the National Technical Information Service, U. S. Department of Commerce, 5285 Port Royal Rd., Springfield, Virginia 22161, (703) 487-4650.

Honeywell

Federal Manufacturing $\&$ Technologies

P. O. Box 419159

A prime contractor with the United States

Kansas City, Missouri

Department of Energy under Contract Number

$64141-6159$

DE-ACO4-76-DP00613.

Honeywell

KCP-613-6306

Distribution Category UC-706

Approved for public release; distribution is unlimited. 
IMAGING SYSTEM FOR THE AUTOMATED DETERMINATION

OF MICROSCOPICAL PROPERTIES

IN HARDENED PORTLAND CONCRETE

C. W. Baumgart, S.P. Cave, K.E. Linder

Published March 2000

Final Report/CRADA Project Accomplishments Summary

CRADA Number 98KCP1069

\section{Imaging System for the Automated Determination of Microscopical Properties in Hardened Portland Concrete}

Project Accomplishments Summary

CRADA Number 98KCP1069

Date: $1 / 31 / 00$
A. Parties

The project is a relationship between

Honeywell FM\&T

$2000 \mathrm{E} 95^{\text {th }}$ Street

PO Box 419159

Kansas City, MO 64141-6159
Revision:

Missouri Highway and Transportation Commission

1617 Missouri Blvd., P.O. Box 270

Jefferson City, Missouri 65102 


\section{B. Background}

Prior to this CRADA, the Missouri Department of Transportation (MoDOT), Research, Development, and Technology, evaluated concrete samples in a manual process as described in ASTM standard C457-90. In this manual process, a concrete core sample is obtained from a section of roadway to be evaluated. These core samples are gathered, and a relatively thin (two to three inches thick) slice is produced. The face of the core sample is then polished. The sample slice is then placed on a linear traverse and illuminated with a light source at a grazing angle. The light source produces strong shadows within the voids and brightly illuminates the edge of the void opposite the light source. This enhances the surface contrast of the sample for the evaluation process.

The sample is then viewed through a 100x microscope and "scanned" by traversing the sample under the microscope and by identifying the type of component (void, aggregate, paste, or gap) traversed along a single scan line. An estimate of the length of the chord traversing each distinct component is recorded. After completion of the scanning process, the measured chord lengths are used to calculate the properties specified in the ASTM standard and other properties designated by MoDOT, which define the air void structure for freeze-thaw resistant concrete. Typically, seven to ten scans are performed along randomly selected lines, with as many as 500,000 sample points per scan line. One of the most critical factors estimated in this process is the percentage of each scan line which crosses an observed void (or air space). In addition, a distribution of void diameters is statistically computed based on the measurement of chord lengths across each detected void. This manual process is rather tedious, with approximately 8-12 hours per concrete sample required to accomplish the evaluation. Also, the consistency of the process can be dependent upon the individual who actually performs the scan.

MoDOT expressed a desire to automate this scanning and evaluation process to: (1) reduce or eliminate the tedious aspects of the process and improve its efficiency; (2) improve the consistency of the scanning process; and (3) capture critical knowledge of the scanning process from a relatively small number of experts currently performing the manual process. Federal Manufacturing \& Technologies (FM\&T) offered to support this effort since there were several aspects of the concrete evaluation process that were quite similar to some processes performed within the Department of Energy (DOE) weapons community. In particular, some of the image processing techniques used in this development effort, as well as some new techniques that were developed during the CRADA, have direct application to nondestructive analysis processes used with the nuclear weapons community.

\section{Description}

During this CRADA, Honeywell FM\&T and MoDOT personnel designed a unique scanning system (including both hardware and software) that can be used to perform an automated scan and evaluation of a concrete sample. The specific goals of the CRADA were:

1. Develop a combined system integration, image acquisition, and image analysis approach to mimic the manual scanning and evaluation process. Produce a prototype system which can: (a) automate the scanning process to improve its speed and efficiency; (b) reduce operator fatigue; and (c) improve the consistency of the evaluation process. 
2. Capture and preserve the baseline knowledge used by the MoDOT experts in performing the evaluation process. At the present time, the evaluation expertise resides in two MoDOT personnel. Automation of the evaluation process will allow that knowledge to be captured, preserved, and used for training purposes.

3. Develop an approach for the image analysis which is flexible and extensible in order to accommodate the inevitable "pathologies" that arise in the evaluation process. Such pathologies include features such as cracks and fissures, voids filled with paste or debris, and multiple, overlapping voids.

FM\&T personnel used image processing, pattern recognition, and system integration skills developed for other Department of Energy applications to develop and test a prototype of an automated scanning system for concrete evaluation. MoDOT personnel provided all the basic hardware (microscope, camera, computer-controlled stage, etc.) for the prototype, supported FM\&T in the acquisition of image data for software development, and provided their critical expert knowledge of the process of concrete evaluation. This combination of expertise was vital to the successful development of the prototype system.

The prototype developed under this CRADA is called ACES, for Automated Concrete Evaluation System. ACES currently provides a baseline capability to analyze a prepared sample of portland cement concrete and to provide estimates of the microscopical properties of the concrete in accordance with the ASTM standard. ACES uses a two-dimensional computer-controlled staging capability to move the sample under a research grade microscope. The image acquisition system used on the prototype consists of a color CCD camera, a frame grabber for image capture, and a dual processor tower PC. In addition, specialized image processing software was developed to identify air voids and extract void characteristics to be used to calculate the portland concrete microscopical properties of interest. All these system components are linked via a graphical user interface which aids the operator in the image acquisition, analysis, and review processes. Figure 1 provides a visual overview of the integration concept for the ACES prototype. 


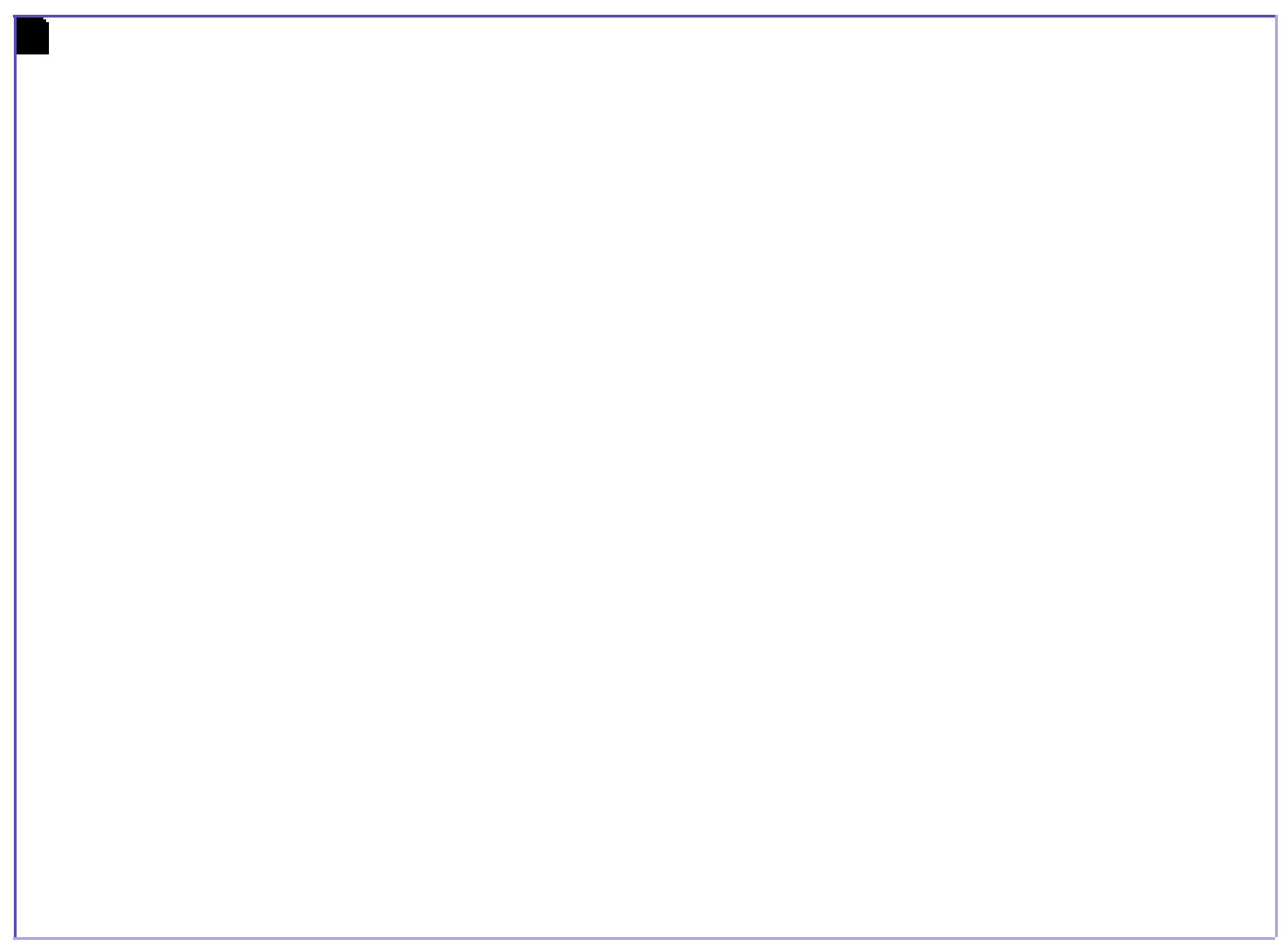

Figure 1. Hardware and data flow concept for automated scanning system

The fundamental image processing steps involve: (1) capture of an image from the microscope field-of-view; (2) application of image enhancement and segmentation techniques to extract salient information from the image; and (3) application of pattern recognition techniques to identify and characterize voids. At the present time, three different segmentation and recognition techniques are applied to each image. These include color segmentation and recognition, shape segmentation and recognition (morphological processing), and line profile segmentation and recognition. In each case, the "object" extracted from an image is characterized with a set of features (characteristics) which are used to uniquely discriminate void regions from other components of the concrete. Depending on the particular segmentation technique, these extracted features are then used as input into either fuzzy logic, neural network, or rule-based recognition techniques to identify which of the detected objects are actually voids and which are background "clutter" objects (coarse aggregate, sand crystals, cracks, etc.). The area and diameter of the identified void are then archived for later use in the calculation of the microscopic properties of the concrete sample as a whole. Following the completion of the scanning and analysis processes, a report is generated in a format identical to that provided by the manual process.

Following the completion of the prototype hardware and software development, a number of validation tests were performed to benchmark the performance of the prototype. These validation tests were based on the use of a relatively small number of concrete samples, but were sufficient to benchmark the baseline performance of the prototype. A review of the results of these tests has revealed the following conclusions and recommendations: 
1. The automated scanning system developed on the CRADA is capable of scanning and acquiring imagery of a concrete sample to a level of resolution sufficient to assess concrete quality in accordance with the ASTM standard.

2. In general, the automated analysis process produces results which are in general agreement with the manually determined results. However, as of this date, the automated results do not agree with the manually determined results to the level of accuracy required by MoDOT. As a result, additional validation of the analysis software will be required before the potential accuracy of the prototype can be unequivocally determined.

3. The automated analysis process provides consistent results, even though additional validation and software development is required to improve its accuracy to a level required by MoDOT.

4. Additional image processing approaches need to be developed to ensure that light gray aggregate and quartz sand crystals are accurately identified. These components of the concrete appear very similar in color to the matrix, resulting in aggregate being classified as paste. Similarly, quartz sand can sometimes be mistaken for a void, resulting in an abnormally large number of void pixels being reported rather than paste or aggregate.

5. There are still a number of "pathologies" that can occur on a concrete sample (merged voids, gaps, cracks, filled voids, etc.) which the analysis software must be able to process. This will require additional software development.

6. A significant number of image analysis, data analysis, and pattern recognition tools (and skills) were developed by FM\&T personnel during the performance of this CRADA. These tools not only provide the mechanism for improvement of the accuracy of the concrete evaluation software, but also provide new and enhanced capabilities for FM\&T in support of the DOE mission.

\section{Expected Economic Impact}

This process will save time and enhance the evaluation process for hardened portland concrete. The Missouri Department of Transportation will quickly realize a savings in the hardened portland concrete evaluation process. Other potential applications for this prototype system include:

- Scanning and evaluation services provided to other state highway departments

- The evaluation of concrete properties for other local, state, and Federal agencies

- The evaluation of concrete properties for the construction industry

- Manufacture of multiple units of the prototype for individual use for all of the above-mentioned organizations.

\section{E. Benefits to DOE}

The image processing approaches and improved image processing capabilities developed on this CRADA can be directly applied in nondestructive evaluation processes in support of weapons surety (for example, the Enhanced Surveillance Program - ESP). The prototype developed for MoDOT provides surface scanning and image capture capability, and can be used to identify and characterize small voids or defects in surfaces (down to 2-3 microns). Surface imaging was used in this project as an efficient and cost-effective alternative to surface profiling. In surface profiling, only one line profile across the sample is generated per scan, whereas with an image, a multitude of profiles is generated with each acquired image. In addition, surface profiling cannot be used to effectively 
measure the diameters of the voids (a MoDOT requirement) and equipment for surface profiling is quite expensive $(\sim 100 \mathrm{~K})$ compared to an imaging system $(\sim \$ 5-10 \mathrm{~K})$.

The algorithms and capabilities developed in this CRADA, plus the enhanced detection resolution to micron levels, can be used to examine optical imagery and identify and characterize small surface defects and flaws in weapons components (electromechanical, microelectronic, and optical). These techniques can also be used to enhance the capabilities of similar tools being developed within the Enhanced Surveillance diagnostics program. Such projects include:

- Neutron Radiography and High Resolution X-ray Tomography. These projects are building inspection tools for the inspection of entire weapons assemblies. This requires the development of image analysis algorithms to resolve fine features (millimeter scale voids and at least 1-mil cracks) with the goal of early detection of potential defects resulting from corrosion, cracking, etc. This CRADA has developed such tools and, as such, represents a capability enhancement over the 1-mil requirement.

- Pit Surface Characterization and Endoscopic Imaging and Optical Coherence Tomography. These projects require the examination and characterization of the surfaces of pits to quantify and document the conditions of the pits. No specific minimum resolution is stated for these projects, but the imaging and analysis techniques that have been developed in this CRADA will provide a resolution capability down to 2-3 microns.

- Ultrasonic Characterization of Assemblies. This project is developing ultrasonic technologies to assess the strengths of bonds in weapons components. The data generated by these techniques is image data, and image analysis and pattern recognition algorithms are required to detect and characterize flaws in the bonds. This CRADA has developed similar algorithms which may be able to enhance the detection and characterization of bond flaws.

FM\&T will make this technology and analysis capabilities available to other DOE researchers working on the Enhanced Surveillance Program projects mentioned above (and others). The technology that has been developed on this CRADA with MoDOT has improved DOE's ability to perform core surveillance of the weapons stockpile and has provided FM\&T personnel with enhanced knowledge and experience which can be used in developing and integrating similar systems for DOE Programs. Without this CRADA, these enhanced detection and characterization techniques would not be available to the Enhanced Surveillance Program to improve the resolution and capabilities of the above-described ESP diagnostic tools.

\section{F. Industry Area}

A variety of industries could benefit from the technology developed under this CRADA. These would include:

- Construction industry, for the evaluation of concrete quality for buildings and roadways.

- Software industry, through the modification and application of the software techniques developed under this CRADA for other imaging, surface profiling, and pattern recognition applications. 
- Medical industry, through the modification of the prototype system for use with microscope slides, or the use of the developed imaging and recognition techniques for the analysis of medical imagery.

- Federal agencies to include the FAA (for quality analysis of concrete used for runways) and the DoD (evaluation of materials for hardened facilities).

\section{G. Project Status}

The prototype system with baseline software was successfully completed in January 2000. Additional system validation and software development is required, however, to ensure that the system provides evaluation results to within a satisfactory level of agreement with the MoDOT experts. However, the system hardware and software presently can be used as a baseline system to develop integrated analysis approaches for any of the other application areas or industries mentioned above.

\section{H. Point of Contact for Project Information}

Ken Bauer

US Department of Energy

Kansas City Area Office

PO Box 410202

Kansas City, MO 64141-0202

Telephone: (816) 997-3917
Dr. Chris W. Baumgart

Honeywell FM\&T

PO Box 5250

Albuquerque, NM 87185-5250

Telephone: (505) 844-2585

Fax: (505) 844-3751

Fax: (816) 997-5059

I. Company Size and Point of Contact

Missouri Department of Transportation

POC: Jim Murray, 573-571-3002 (voice), 573-522-8416 (fax)

\section{J. Project Examples}

The following items are provided as attachments to this PAS:

- A flyer produced by FM\&T describing the general nature of the CRADA project

- Photographs of the integrated system

\section{K. Technology Commercialization}

At the present time, there is no immediate plan to commercialize the prototype system. 
Additional software validation and development is required before a final determination can be made as to the potential marketability of this system. However, an invention disclosure has been filed jointly by FM\&T and MoDOT on the prototype system.

\section{Release of Information}

I have reviewed the attached Project Accomplishment Summary prepared by Honeywell FM\&T and agree that the information about our CRADA may be released for external distribution.

Original signed by

Name: Jim Murray

Organization:

Title: State Research, Development and Technology Engineer
$3-1-2000$

Date

Missouri Department of Transportation

Research, Development \& Technology Division

1617 Missouri Blvd.

PO Box 270

Jefferson City, MO 65102-0270 

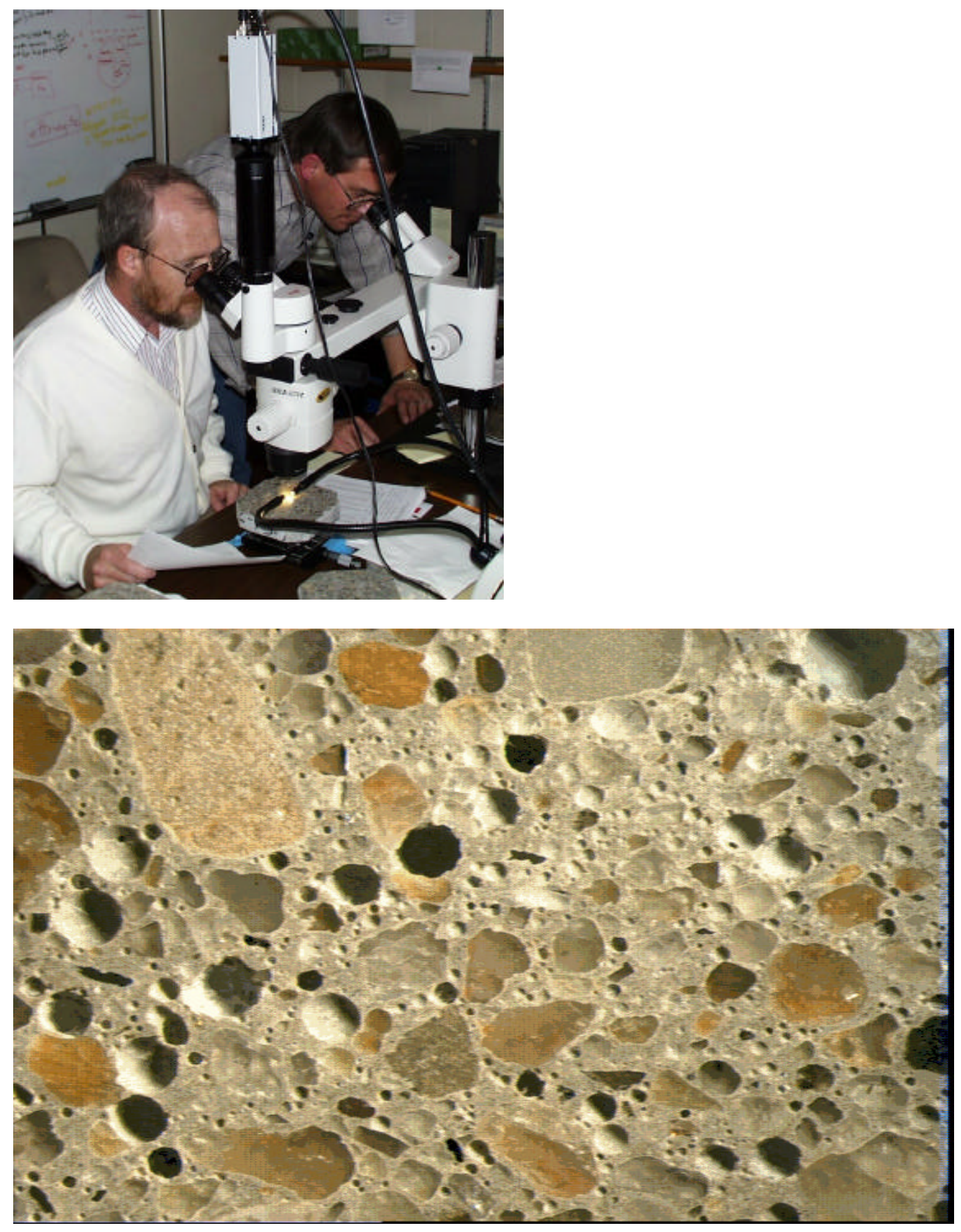

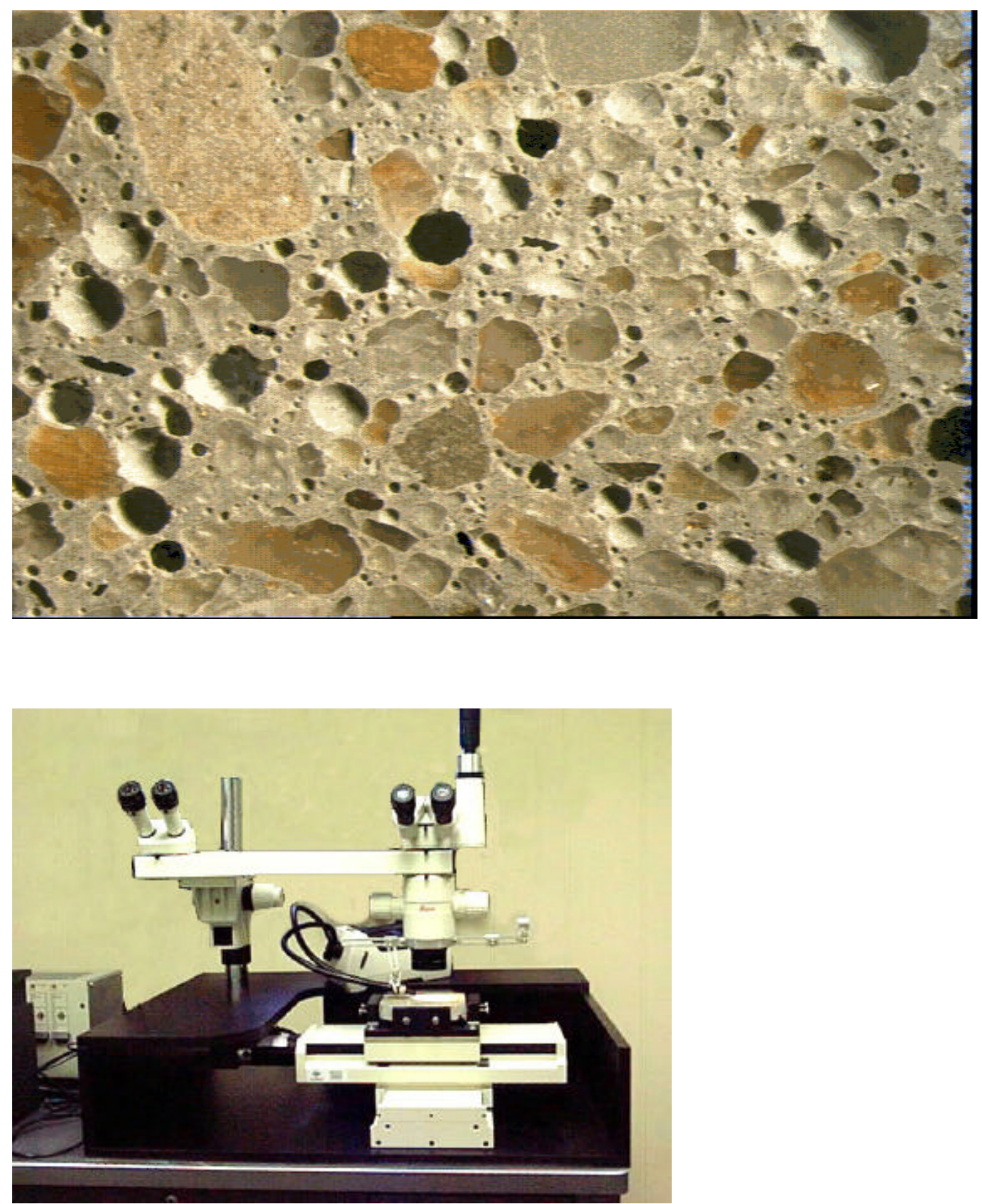

Prototype ACES System 


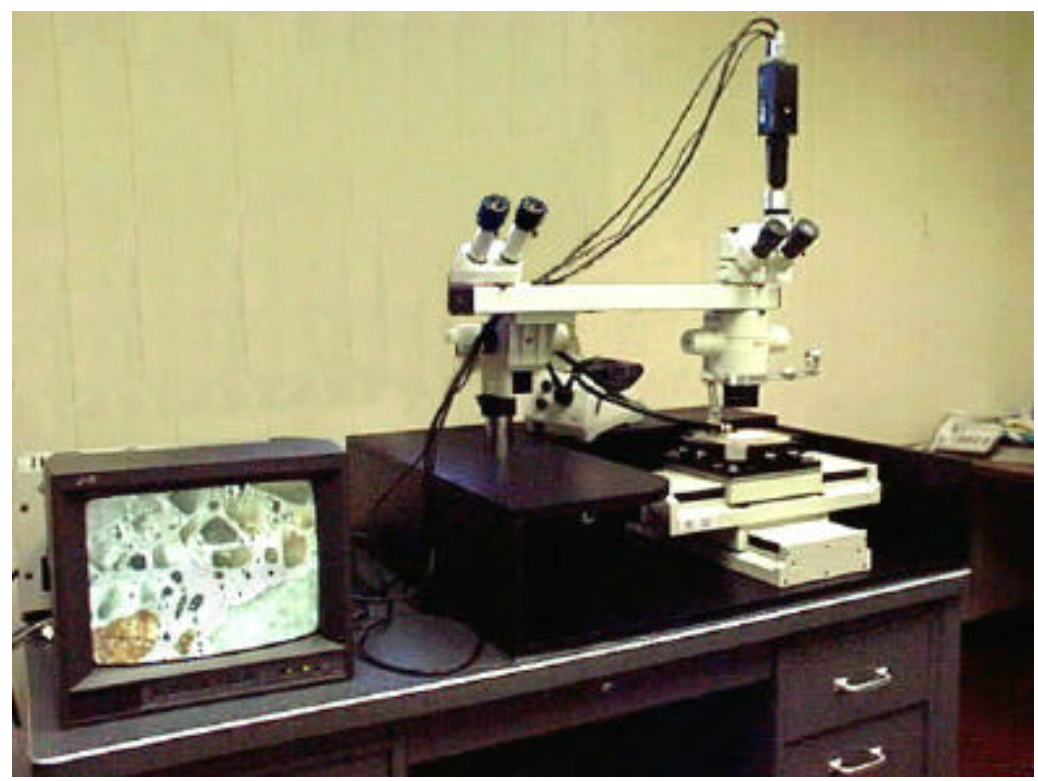

Prototype ACES System 